\title{
Patterns of anticoagulation and clinical outcomes in atrial fibrillation: insights from a single institution registry
}

\author{
(DIvana Jurin, \\ DMarko Lucijanić, \\ (D)Andjela Jurišić, \\ (DT)Tomislava Bodrožić \\ Džakić Poljak, \\ DiD Jasmina Ćatić, \\ (1DBoris Starčević, \\ DIrzal Hadžibegović*
}

University Hospital Dubrava Zagreb, Croatia
RECEIVED:

September 4, 2019

ACCEPTED:

September 16, 2019

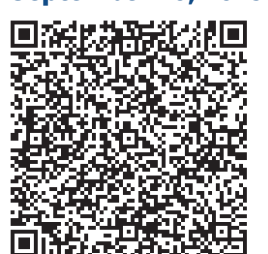

KEYWORDS: atrial fibrillation, stroke prevention, anticoagulation.

CITATION: Cardiol Croat. 2019;14(9-10):239. | https://doi.org/10.15836/ccar2019.239

*ADDRESS FOR CORRESPONDENCE: Irzal Hadžibegović, Klinička bolnica Dubrava, Avenija Gojka Šuška 6, HR-10000 Zagreb, Croatia. / Phone: +385-91-5333-091 / E-mail: irzalh@gmail.com

ORCID: Ivana Jurin, https://orcid.org/0000-0002-2637-9691 • Marko Lucijanić, https://orcid.org/0000-0002-1372-2040 Anđela Jurišić, https://orcid org/0000-0001-8316-4294 • Tomislava Bodrožić Džakić Poljak, https://orcid.org/0000-0002-7293-3972 Jasmina Ćatić, https://orcid.org/0000-0001-6582-4201 • Boris Starčević, https://orcid.org/0000-0002-3090-2772 Irzal Hadžibegović, https://orcid.org/0000-0001-9139-5009

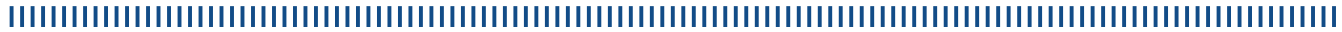

Aim: To investigate clinical outcomes in patients with atrial fibrillation exposed to different types of anticoagulant drugs within a single institution retrospective registry.

Patients and Methods: A cohort of 758 consecutive patients with non- valvular atrial fibrillation receiving anticoagulation therapy after first referral to our institution in a period from 2012 to 2018 . We analyzed demographic and clinical data, first choice anticoagulation therapy and time of any of the following clinical outcomes: death, thromboembolic event, and major bleeding and performed univariate and multivariate analyses.

Results: There were 434 (57\%) patients receiving warfarin, and 178 (23\%) and 146 (20\%) patients receiving dabigatran and AntiXa, respectively. There was a statistically significant trend of increase in frequency of DOAC use over time $(\mathrm{P}=0.002)$. Patients anticoagulated with warfarin were significantly older, had lower eGFR and LVEF, had more frequent chronic heart failure, coronary artery disease, permanent atrial fibrillation, higher $\mathrm{CHA}_{2} \mathrm{DS}_{2}$ VASC and higher HAS-BLED scores than DOAC receiving patients ( $\mathrm{P}<0.05$ for all comparisons). Only $11 \%$ of patients on warfarin had acceptable recorded time in therapeutic range values. Univariately, there were significantly more events in patients treated with warfarin than with DOACs ( $\mathrm{p}<0,001$ for all events). After adjusting for age, eGFR, and EFLV time to death ( $\mathrm{HR}=5.08,95 \% \mathrm{CI}(2.23-11.61), \mathrm{P}<0.001)$ and time to thromboembolic event (HR=3.38, 95\% CI $(1.30-11.12)$, $\mathrm{P}=0.045)$ were significantly shorter in warfarin then in DOAC treated patients, whereas time to major bleeding (HR=1.01, 95\% CI (0.84-2.55), $\mathrm{P}=0.110)$ did not differ significantly.

Conclusion: Patients with higher risk received warfarin more frequently, possibly due to reimbursement issues. Patients receiving warfarin experience significantly higher adjusted risks of thrombosis and death, probably reflecting differences in patients' characteristics and predetermined risks for stroke or other cardiovascular events at baseline. Although the use of DOACS increased over time, changes in DOAC availability for all patients should be made to optimize patterns of anticoagulation in atrial fibrillation. ${ }^{1}$

LITERATURE IIIIIIIIIIIIIIIIIIIIIIIIIIIIIIIIIIIIIIIIIIIIIIIIIIIIIIIIIIIIIIIIIIIIIIIIIIIIIIIIIIIIIIIIIIIIIIIIIIIIIIII

1. Potpara TS, Dan GA, Trendafilova E, Goda A, Kusljugic Z, Manola S, et al; BALKAN-AF Investigators. Stroke prevention in atrial fibrillation and 'real world' adherence to guidelines in the Balkan Region: The BALKAN-AF Survey. Sci Rep. 2016 Feb 12;6:20432. https://doi.org/10.1038/srep20432 